\title{
Caracterização da resposta imune gerada pelo direcionamento de uma proteína de Plasmodium para as células dendríticas
}

Tese apresentada ao Programa de Pós-Graduação em Biologia da Relação patógeno-Hospedeiro de Instituto de Ciências Biomédicas da Universidade de São Paulo, para obtenção do Título de Doutor em Ciências.

Área de Concentração: Biologia da Relação PatógenoHospedeiro

Orientadores Dra Silvia Beatriz Boscardin

Dr Rogério Amino

Versão Original 


\section{Resumo}

Panatieri RH. Caracterização da resposta imune gerada pelo direcionamento de uma proteína de Plasmodium para as células dendríticas. [Tese (Doutorado em Parasitologia)]. São Paulo: Instituto de Ciências Biomédicas, Universidade de São Paulo; 2016.

Em geral, a imunidade protetora contra muitos patógenos depende da geração e manutenção do repertório de linfócitos $T$ de memória, e de sua manutenção por longos períodos de tempo após um contato inicial com o patógeno. Sabemos que a geração dessas células está correlacionada com a ativação de células do sistema imune específicas ao parasito e com a apresentação de antígenos pelas células dendríticas (DCs). Essas células têm um papel central no sistema imune, conectando as respostas imunes inata e adaptativa. Nos últimos anos, o direcionamento de antígenos para as DCs tem sido estudado como um novo método vacinal. Essas estratégia consiste em entregar antígenos diretamente para DCs usando anticorpos monoclonais que reconhecem receptores expressos na superfície dessas células. Sendo assim, o principal objetivo desse trabalho foi direcionar uma proteína de Plasmodium para a subpopulação DEC205 ${ }^{+}$de DCs. Para isso camundongos foram imunizados com duas doses do anticorpo monoclonal aDEC205.CS na presença de poly I:C como adjuvante, e então desafiados dias após a segunda imunização, com esporozoítos de $P$. yoelii. Como controles da proteína não direcionada, utilizamos o anticorpo monoclonal fusionado desnaturado, sem capacidade de reconhecer o receptor, e também a proteína recombinante (CSr). A proteína direcionada não protegeu camundongos do desafio, mas a proteína não direcionada protegeu, alcançando níveis de proteção estéril em torno de $100 \%$ em alguns casos. Na tentativa de entender os mecanismos envolvendo esses resultados, observamos que a resposta humoral pareceu ocupar um papel central nos mecanismos de proteção. Encontramos correlação entre a quantidade dos anticorpos e a proteção relativa dos animais imunizados com a proteína não direcionada. Além disso, utilizando anticorpos monoclonais que reconhecem diferentes porções da proteína, demonstramos que a região conhecida como 'major repeat' pode ser utilizada como alvo direto de pesquisas em vacinas contra malária, para a geração de uma resposta imune protetora.

Palavras-chave: Malária. Células dendríticas. DEC205. Anticorpos monoclonais. 


\begin{abstract}
Panatieri $\mathrm{RH}$. Characterization of the immune response when targeting a protein from Plasmodium to dendritic cells [Ph.D Thesis (Parasitology)]. São Paulo: Instituto de Ciências Biomédicas, Universidade de São Paulo; 2016.

In general, protective immunity against many pathogens depends on the generation and maintenance of $T$ lymphocyte memory repertoire, and the survival of cells for a long period of time after initial contact with pathogens. We know that the generation of these cells is correlated with the activation of parasite-specific immune cells and the presentation of antigens for dendritic cell (DCs). These cells have a central role in immune system, connecting innate and adaptive immunity. In the last few years, targeting antigens to DCs has been studied as a new vaccination method. This strategy consists in the delivery of antigens directly to DCs using monoclonal antibodies which recognizes receptors expressed on the surface of these cells. So, the main objective of this work was target circunsporozoite protein (CSP), an antigen from Plasmodium, to a DEC205 ${ }^{+}$(DC) subset. Mice were immunized twice using fused antibodies aDEC205.CS with Poly I:C as adjuvant, and then challenged a few days after the second dose using Plasmodium yoelii sporozoites (spz). As control, non-targeting protein was used denatured antibody and CS recombinant protein (CSr). Targeting protein did not protect mice from challenge, but non-targeting $\mathrm{CS}$ lead, in some cases, to $100 \%$ of protection. Trying to understand the mechanisms involving these results, we observed that humoral response seems to be the central part in this process. We found correlation between levels of antibody response with protection, with high levels of anti-CS total IgG in mice immunized with non-targeting protein. Besides, using monoclonal antibodies, which recognizes major and minor repeat, we were able to map major repeat as a potential target for new researches in malaria vaccine for generation of protective immune response.
\end{abstract}

Keywords: Malaria. Dendritic cells. DEC205. Monoclonal antibodies. 
1 INTRODUÇÃO 


\subsection{Malária}

A malária é uma doença endêmica em diversos países de regiões tropicais e subtropicais. Causada pelo Plasmodium, um parasito do filo apicomplexa, em 2013 infectou aproximadamente 198 milhões de pessoas e causou cerca de 584 mil mortes, a maioria de crianças menores de 5 anos, em decorrência das complicações causadas pela infecção (1).

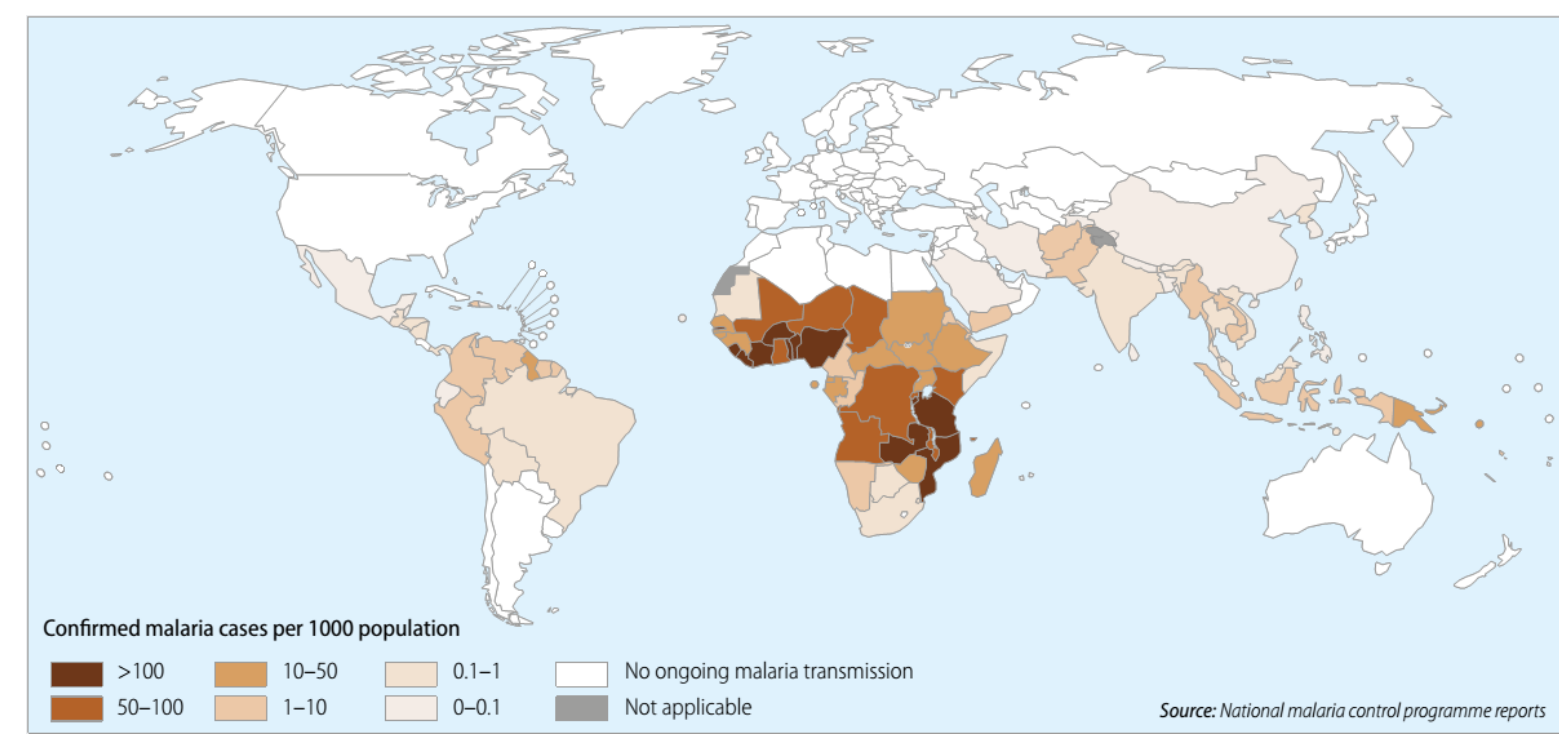

Figura 1 - Mapa esquemático apontando as regiões de áreas endêmicas, demarcadas em tonalidades diferentes, referenciando o número de casos em cada região por mil habitantes Fonte: World Malaria Report 2014, WHO.

No mesmo período no Brasil a incidência foi de aproximadamente 200 mil casos, concentrados principalmente na região Amazônica (1). Em mais de 80\% dos casos relatados no país as infecções são causadas por $P$. vivax, uma das espécies do parasito que infectam os seres humanos.

Além dessa, existem outras espécies que infectam humanos, como é o caso do P. falciparum, com infecções geralmente confinadas à regiões tropicais, e que juntamente com o $P$. vivax somam cerca de $95 \%$ das infecções no mundo (2); o $P$. 
knowlesi, que apesar de ser mais conhecido por causar a doença em macacos, alguns casos de malária humana nas regiões de Borneo, Tailândia e Filipinas, tem sido atribuídos à essa espécie $(3,4)$. Também são relatados casos de infecções ocasionadas por $P$. ovale e $P$. malariae, com a maioria dos casos registrados na região da África Oriental e na região da África subsaariana, respectivamente (2).

Nessas regiões tropicais e subtropicais do globo o clima é propício para o desenvolvimento do ciclo de vida de mosquitos, como os do gênero Anopheles, e são as fêmeas dessa espécie os vetores ideais para a transmissão desses parasitos.

Fêmeas do mosquito carreando esporozítos na sua glândula salivar injetam esses parasitos na pele do hospedeiro vertebrado durante nova hematofagia. Ao contrário do que se acreditava, esses parasitos não são injetados diretamente na corrente sanguínea, na verdade são depositados em diferentes partes da pele antes de atingirem os vasos, fato que parece não seguir um padrão randômico de movimentação (5). Quando na corrente sanguínea, o que pode levar de minutos a horas a partir do momento da picada, os esporozoítos migram até o fígado, onde invadem hepatócitos. Durante esse período os parasitos se dividem e se diferenciam em merozoítos, formas capazes de invadir eritrócitos. Para sair do fígado e chegar a corrente sanguínea novamente os parasitos conseguem se desprender dos hepatócitos em formações chamadas merossomos, constituídas de parte do citoplasma da células infectadas (6). 


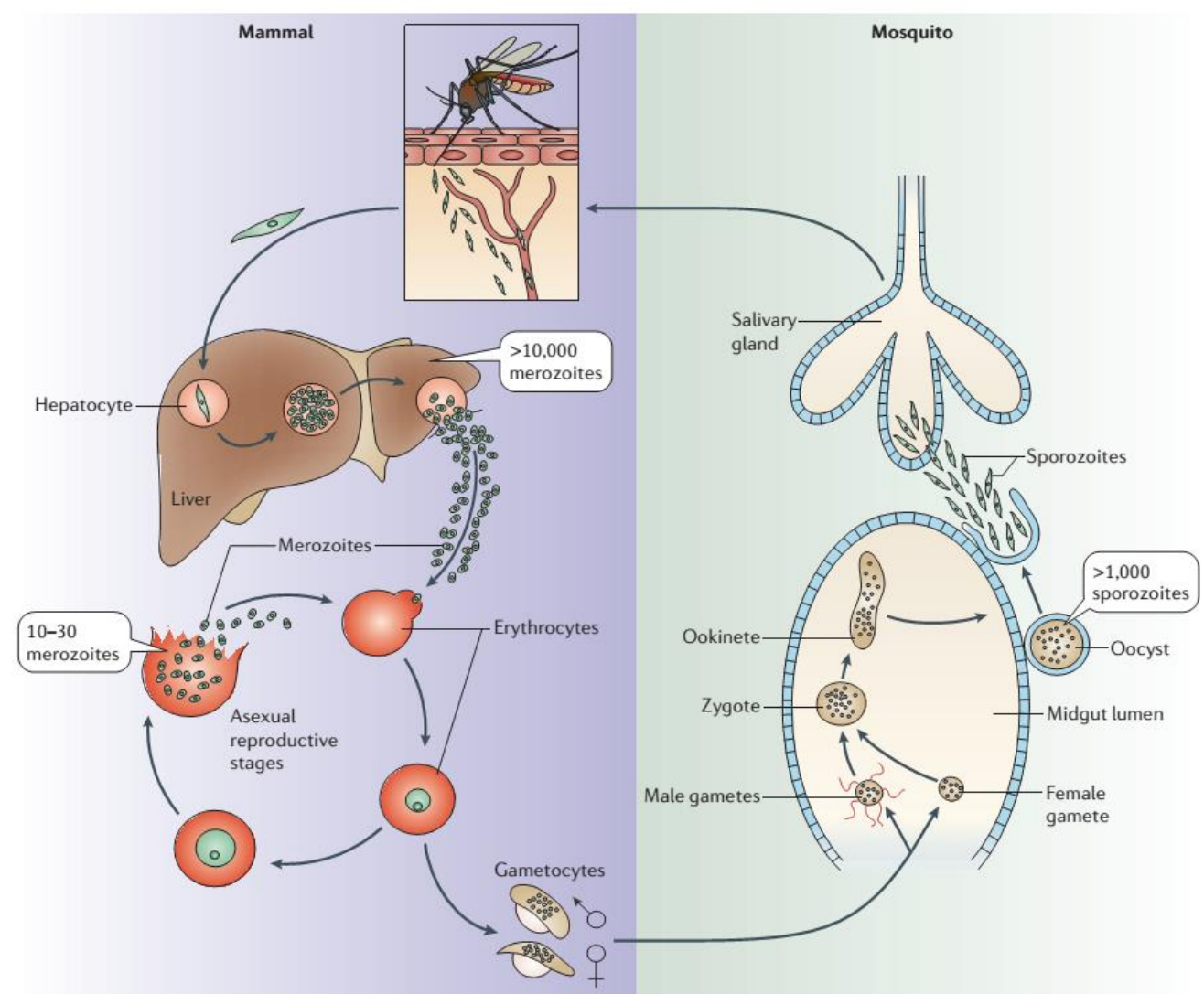

Figura 2 - Desenho esquemático do ciclo de desenvolvimento do parasito, apresentando as duas fases que ocorrem dentro do hospedeiro vertebrado e a fase sexuada que ocorre dentro do hospedeiro invertebrado. Fonte: Menard, R. 2015; doi:10.1038/nrmicro3111

Essas formações se rompem ao atingir o sangue liberando os merozoítos que irão invadir hemácias, iniciando a fase sanguínea do desenvolvimento (Figura 2).

Nesse estágio, após invadir os glóbulos vermelhos, o parasito se replica originando novos merozoítos que, ao serem liberados após hemólise, irão infectar novas células. Durante a replicação, alguns parasitos se diferenciam em formas gametocíticas capazes de infectar o vetor invertebrado. No momento da hematofagia, o mosquito ingurgita os gametócitos que irão, de forma sexuada, originar os oocistos contendo centenas de esporozoítos capazes de infectar o hospedeiro vertebrado.

Dentre os sintomas, geralmente observa-se que o paciente é acometido por anemia como consequência do rompimento direto das hemácias durante a replicação 
do parasito, pela lise e remoção de hemácias pelo sistema imune ou pela supressão medular que pode ocorrer em determinados casos.

Grande parte dos sintomas clínicos atribuídos a infecção pelo Plasmodium são decorrentes do estágio sanguíneo de replicação. Febre alta, associada a calafrios, sudorese, dores de cabeça e pelo corpo podem seguir dias após a infecção.

Mesmo com um quadro, na maioria dos casos, sintomático, como descrito acima, a resposta imunológica protetora, quando gerada, requer uma reestimulação constante das células imunes, com antígenos do parasito, e mesmo assim, o hospedeiro permanece suscetível a reinfecção.

\subsection{Resposta Imune}

Em geral, a imunidade protetora contra vários organismos patogênicos depende da indução de resposta imune inata, após um primeiro contato, e da geração e manutenção do repertório de linfócitos de memória.

No caso de infecções pelo Plasmodium, estudos utilizando modelos murinos de infecção pelo $P$. yoelii e $P$. chabaudi demonstram, respectivamente, a importância da resposta imune inata, em limitar a carga parasitária (7), e da resposta imune adaptativa, na eliminação de estágios sanguíneos de infecção (8).

O sistema imune inato, através de células e moléculas solúveis presentes no sangue, fluidos extracelulares e secreções epiteliais, consegue enfraquecer ou eliminar o Plasmodium (9). Estudos com modelo murino de infecção pelo $P$. chabaudi demonstram, por exemplo, que na ausência de células NK (do inglês 'Natural killer') a parasitemia, na fase aguda da infecção e durante a recrudescência, é mais elevada (8). Em estudos com o $P$. yoelii, observa-se que a produção de IFNy por essas células 
está envolvida na cura espontânea da infecção durante o estágio sanguíneo de infecção $(8,10)$.

Além das células NK, células da linhagem monocítica incluindo monócitos, células dendríticas e macrófagos apresentam um papel indispensável durante a infecção (11). As modificações que ocorrem na superfície de eritrócitos infectados (12) ativam monócitos de forma direta, através da interação de receptores com proteínas expressas pelo parasito na superfície das células infectadas (13-15); ou de forma indireta, por deposição de moléculas do sistema complemento ativadas (16) e de anticorpos, que, por sua vez, são capazes de ativar os monócitos, via receptores de complemento e receptores Fc $(17,18)$, mediando a proteção por mecanismos envolvendo fagocitose. Os monócitos ativados nos tecidos podem se diferenciar em macrófagos, quando estimulados por M-CSF, ou em DCs, quando estimulados por IL4 e GM-CSF, por exemplo (9). Tanto macrófagos quanto DCs expressam receptores do tipo Toll (do inglês "toll like receptor" - TLR), que funcionam como sensores para a presença de micróbios (Tabela 1). A indução desses receptores promove diferenciação e ativação de DCs capazes de mediar mecanismos de resposta imune inata, por exemplo, através da produção de IFNy e TNFa capazes de ativar macrófagos e células NK. Essa ativação pode ocorrer por contato direto através da expressão de moléculas co-estimulatórias CD80 e de algumas citocinas como IL15, IL12 e IFNa/ $\beta$ (19).

Além de expressar diferentes citocinas, durante a resposta imune inata, as DCs também são capazes de mobilizar linfócitos $\mathrm{T}$ naive. Essa propriedade intrínseca permite a indução de respostas imunes adaptativas através de três características básicas importantes: 1) sua distribuição por todo o corpo, especialmente na periferia 
onde 2) através de receptores endocíticos expressos na membrana, conseguem capturar antígenos, iniciando os processos de maturação e migração para os órgãos linfoides periféricos, e então 3) promovem a ativação e expansão de linfócitos específicos, iniciando a resposta imune adaptativa. Essa resposta, em um contexto infeccioso, pode induzir uma resposta de memória, envolvendo células capazes de responder a um antígeno por longos períodos, mesmo após o término do processo de infecção (20).

Durante a malária uma resposta celular de memória correlaciona-se tanto com a ativação de linfócitos T específicos quanto com a apresentação de antígenos pelas DCs. Estudos utilizando modelos murinos de infecção pelo Plasmodium mostram que a proteção induzida por imunizações com esporozoítos irradiados requer resposta celular com ativação de linfócitos $\mathrm{T} \mathrm{CD4}^{+}(21)$ importantes na expansão de linfócitos $\mathrm{T}$ CD8 ${ }^{+}$específicos para antígenos da fase pré-eritrocítica, por exemplo $(22,23)$.

\subsection{Vacinas contra Malária}

Apesar dos esforços contínuos, métodos de prevenção são difíceis e nenhuma droga é universalmente eficaz (2). Por esse motivo, são diversos os grupos de pesquisa que atualmente buscam o desenvolvimento de formulações vacinais capazes de gerar uma reposta imune protetora e de longa duração contra antígenos do Plasmodium.

Buscando por essa resposta, algumas pesquisas têm demonstrado o efeito protetor da utilização de esporozoítos irradiados em ensaios de imunização $(24,25)$. O estudo mais recente realizado por Hoffman e cols (26) demonstrou que todas as 
pessoas submetidas a cinco imunizações com $1,35 \times 10^{5}$ esporozoítos irradiados (iSpz) de $P$. falciparum ficaram protegidas.

Mesmo a Mosquirix ${ }^{\mathrm{TM}}$ ou RTS,S, uma formulação vacinal desenvolvida e testada pela empresa GlaxoSmithKline (GSK), e que possui uma aceitação positiva pelas agências de saúde europeias, apresentou $50 \%$ de proteção em testes clínicos realizados em áreas endêmicas.

Embora os resultados sejam promissores, essa é uma estratégia que demanda alto investimento, o que pode dificultar sua distribuição e administração para a população em geral.

Nos últimos 10 anos, mais de 40 vacinas foram desenvolvidas na tentativa de controlar a infecção pelo Plasmodium sendo testadas em ensaios clínicos (27).

Assim como a Mosquirix ${ }^{\mathrm{TM}}$, a maior parte dessas formulações tem como alvo proteínas do parasito expressas na fase hepática do ciclo de desenvolvimento; uma outra parte busca como alvos proteínas da fase eritrocítica do desenvolvimento. Em ambos os casos o objetivo é o desenvolvimento de proteção mediante a indução de resposta celular por linfócitos $\mathrm{T} \mathrm{CD}^{+}$ou resposta humoral associada ao desenvolvimento de linfócitos $\mathrm{T} \mathrm{CD}^{+}$específicos a antígenos do parasito, respectivamente (27).

Mesmo promissores, os níveis de proteção obtidos estão ainda abaixo dos ideais, havendo a necessidade, não somente da administração de doses sequencias da vacina, mas também da utilização de métodos de controle dos mosquitos vetores, para que se atinja um maior número dentro da população.

Por esse motivo, as pesquisas em vacinas contra malária buscam hoje não somente por novas formulações, mas também por novos métodos vacinais que 
aprimorem a resposta imune de longa duração contra antígenos do Plasmodium, e que sobretudo, consigam induzir proteção maior.

\subsection{Direcionamento de antígenos para as Células Dendríticas}

Na última década, uma estratégia vacinal, utilizada com eficácia na geração de respostas imunes celular e humoral contra diferentes patógenos, consiste no direcionamento de antígenos para DCs utilizando anticorpos monoclonais que reconhecem receptores endocíticos expressos na membrana dessas células $(28,29)$.

As DCs são centrais na indução de respostas adaptativas tanto no contexto de infecções causadas por patógenos quanto em imunizações, sendo também importantes para manutenção da tolerância periférica $(30,31)$. Elas podem ser divididas em dois subtipos principais: as DCs convencionais (cDCs) e as DCs plasmocitóides (pDCs). As cDCs podem ser subdivididas pela expressão de moléculas de superfície $(32,33)$, como a cadeia alfa da molécula CD8 (CD8 $\alpha$ ) e a integrina CD11b (34). DCs $C D 8 \alpha^{+}$e CD11 $b^{+}$apresentam expressão diferenciada de receptores do tipo Toll (TRL) e receptores para lectinas, como por exemplo DEC205 (CD205), Clec9A e langerina, expressos principalmente em DCs CD8 $\alpha^{+}$. As DCs $\mathrm{CD}_{11} \mathrm{~b}^{+}$expressam exclusivamente o receptor de lectinas DCIR2 $(35,36)$. Além disso, essas subpopulações são encontradas em diferentes regiões do linfonodo, sendo as DCs $C D 8 \alpha^{+} D E C 205^{+}$encontradas majoritariamente na zona de células $T$, enquanto as DCs CD8a ${ }^{-} \mathrm{DCIR}^{+}$são encontradas na polpa vermelha e na zona marginal $(34,36)$. Essas características quanto a expressão de receptores de membrana e a localização dessas DCs em regiões distintas dentro dos órgãos linfoides secundários, podem 
indicar propriedades funcionais diferentes para essas subpopulações. O direcionamento de antígenos para cada subpopulação pode também contribuir para o esclarecimento das funções de cada subpopulação. Estudos recentes mostraram que as DCs CD11 b ${ }^{+}$DCIR2 ${ }^{+}$produzem mais IL4 e expressam também quimiocinas capazes de atrair linfócitos $\mathrm{T} \mathrm{CD4}^{+}$e promover sua ativação. Por outro lado, as DCs CD8a ${ }^{+}$DEC205 ${ }^{+}$expressam as citocinas IL12 e IL15 que estão envolvidas na diferenciação de linfócitos T citotóxicos $(37,38)$ e na polarização da resposta imune para o perfil Th1 (36). Além disso, essa subpopulação tem a capacidade de promover apresentação cruzada de antígenos endocitados via moléculas de MHC I para células $\mathrm{T} \mathrm{CD8}^{+}$, fato importante quando procuramos induzir imunidade protetora contra infecções pelo Plasmodium utilizando antígenos expressos na fase hepática de seu desenvolvimento.

Vários estudos têm demonstrado a eficiência do direcionamento de antígenos utilizando como alvo o receptor endocítico DEC205. Em 2001, Hawiger e cols (28) demonstraram a necessidade da utilização de estímulos de maturação para as DCs na indução de resposta imune utilizando o direcionamento de antígenos com um anticorpo monoclonal aDEC205. Nesse estudo, o anticorpo monoclonal híbrido aDEC205 acoplado a proteína HEL (do inglês 'hen egg lysozyme') foi utilizado em testes de imunização, com ou sem estímulo de maturação. Camundongos imunizados apenas com o anticorpo monoclonal híbrido desenvolveram tolerância, com deleção de células $\mathrm{T}$ específicas ao antígeno. Por outro lado, a imunização com anticorpo monoclonal híbrido juntamente com um estímulo de maturação promoveu ativação prolongada de células T e imunidade (28). Da mesma forma, Bonifaz e cols. (39), utilizando anticorpo monoclonal aDEC205 acoplado a OVA, também observaram a 
indução de tolerância em testes de imunização sem estimulação, fato que se modificou quando a imunização ocorreu juntamente com aCD40, um estímulo de maturação que levou à ativação prolongada de células T $C D 4^{+}$e $C D 8^{+}(40)$.

Em modelo de EAE (encefalite experimental aguda), o direcionamento de antígenos também foi capaz de induzir tolerância à MOG (do inglês 'myelin oligidendrocyte glycoprotein') (41), peptídeo que induz a inflamação no sistema nervoso central em conjunto com a administração de toxina diftérica (42). $O$ anticorpo monoclonal aDEC205 acoplado à OVA foi utilizado em outro estudo no qual camundongos foram imunizados juntamente com dois estímulos de maturação, aCD40 e poly I:C. A geração de resposta humoral específica foi medida contra o hapteno NP após a administração de uma dose de reforço com a proteína OVA-NP. Boscardin e cols. (43) observaram a geração de uma resposta de células T auxiliares capaz de induzir uma resposta humoral específica. No mesmo trabalho, a proteína circumsporozoíta utilizada em fusão com o anticorpo monoclonal aDEC205 foi efetiva na geração de resposta de células T específicas ao antígeno, auxiliando na geração de anticorpos contra a proteína em questão (44). A ativação específica do sistema imune também foi observada em estudos com a proteína Gag p24 do vírus HIV direcionada para as DCs utilizando anticorpos monoclonais contra o receptor DEC205. Nesse caso o direcionamento foi capaz de aumentar a produção de IFNy e IL2 por células T CD4 ${ }^{+}(45)$ e de levar à proteção contra o desafio com vírus vaccínia expressando a proteína Gag recombinante (29).

Em estudos utilizando o antígeno LcrV de Yersinia pestis, o direcionamento para DCs foi efetivo em gerar resposta imune celular com aumento de células T CD4 ${ }^{+}$ 
produtoras de IFNy e resposta imune humoral com produção de anticorpos IgG2a e IgG2c específicos (46). 
6 CONCLUSÕES 
Quando iniciamos o projeto tínhamos como foco aumentar a capacidade protetora da resposta imune gerada utilizando um novo método vacinal. Nossa hipótese havia sido fundamentada em dados mostrando que o direcionamento induzia resposta imune celular e humoral contra antígenos como OVA e, também, contra a proteína CS de $P$. yoelii, mas sem ensaios que demonstrassem correlação com a capacidade protetora dessa resposta gerada. Com objetivos centrados na busca por repostas que corroborassem ou refutassem nossa hipótese, utilizamos o anticorpo aDEC205.CS para direcionar esse antígeno e verificar se a resposta gerada era capaz de proteger animais contra o desafio.

A medida que avançamos nossos experimentos, observamos que nossos controles de proteína não direcionada foram capazes de proteger os animais em índices de até $100 \%$ em alguns casos, diferente dos nossos grupos experimentais, que receberam a proteína direcionada, onde não houve proteção.

Ao longo do trabalho fizemos diversos questionamentos, na tentativa de entender esses resultados, mas muitos permaneceram sem resposta. Algumas dessas questões para serem respondidas requerem soluções a longo prazo, como por exemplo, a pesquisa para entender a influência da avidez e dos isotipos de IgG na proteção relativa aos grupos controles.

Acreditamos que esse trabalho trará bons resultados. Por isso estamos investindo em meios de responder às questões que ficaram em aberto. Novas técnicas estão sendo empregadas para que possamos entender, de forma mais precisa, o papel de cada componente e a qualidade da resposta imune na 
proteção observada. Desenvolvimento de anticorpos monoclonais, modificação de isotipos, são algumas das técnicas a serem empregadas em novos experimentos.

Nosso pensamento foi sempre em busca de meios que possam trazer a ciência mais próxima de uma solução eficaz no combate de uma doença que tem como principais vítimas crianças. 
REFERÊNCIAS 


\section{Referências*}

1. WHO | World Malaria Report 2013. World Health Organization; [cited 2014 Oct 8]; Available from: http://www.who.int/malaria/publications/world_malaria_report_2013/en/

2. Garcia LS. Malaria. Clin Lab Med [Internet]. 2010 Mar [cited 2012 Mar 6];30(1):93-129. Available from: http://www.ncbi.nlm.nih.gov/pubmed/20513543

3. Jongwutiwes S, Putaporntip C, Iwasaki T, Sata T, Kanbara H. Naturally Acquired Plasmodium knowlesi Malaria in Human, Thailand. Emerg Infect Dis [Internet]. 2004 Dec [cited 2015 Sep 18];10(12):2211-3. Available from:

http://www.pubmedcentral.nih.gov/articlerender.fcgi?artid=3323387\&tool=pmcentrez\&re ndertype $=$ abstract

4. Singh B, Sung LK, Matusop A, Radhakrishnan A, Shamsul SS, Cox-Singh J, et al. A large focus of naturally acquired Plasmodium knowlesi infections in human beings. Lancet [Internet]. 2004 Mar [cited 2015 Oct 7];363(9414):1017-24. Available from: http://www.sciencedirect.com/science/article/pii/S0140673604158364

5. Formaglio P, Amino R. Looking for blood. Elife [Internet]. eLife Sciences Publications Limited; 2015 Oct 6 [cited 2015 Oct 7];4:e11284. Available from:

http://elifesciences.org/content/4/e11284.abstract

6. Sturm A, Amino R, van de Sand C, Regen T, Retzlaff S, Rennenberg A, et al. Manipulation of host hepatocytes by the malaria parasite for delivery into liver sinusoids. Science [Internet]. 2006 Sep 1 [cited 2015 Sep 6];313(5791):1287-90. Available from: http://www.ncbi.nlm.nih.gov/pubmed/16888102

7. Choudhury HR, Sheikh NA, Bancroft GJ, Katz DR, De Souza JB. Early nonspecific immune responses and immunity to blood-stage nonlethal Plasmodium yoelii malaria. Infect Immun [Internet]. 2000 Nov [cited 2015 Oct 8];68(11):6127-32. Available from: http://www.pubmedcentral.nih.gov/articlerender.fcgi?artid=97689\&tool=pmcentrez\&rend ertype=abstract

8. Mohan K, Moulin P, Stevenson MM. Natural killer cell cytokine production, not cytotoxicity, contributes to resistance against blood-stage Plasmodium chabaudi AS infection. J Immunol [Internet]. 1997 Nov 15 [cited 2015 Oct 8];159(10):4990-8. Available from: http://www.ncbi.nlm.nih.gov/pubmed/9366426

9. Murphy KM. Immunobiology. 2011. In: Janeaway CA. [ed]. Janeaway's Immunolbiology. 8 ed. London and New York: Garland Scince Taylor and Francis Group; 2011. Página 59. 
10. De Souza JB, Williamson $\mathrm{KH}$, Otani T, Playfair JH. Early gamma interferon responses in lethal and nonlethal murine blood-stage malaria. Infect Immun [Internet]. 1997 May [cited 2015 Oct 14];65(5):1593-8. Available from:

http://www.pubmedcentral.nih.gov/articlerender.fcgi?artid=175180\&tool=pmcentrez\&ren dertype $=$ abstract

11. Chua CLL, Brown G, Hamilton JA, Rogerson S, Boeuf P. Monocytes and macrophages in malaria: protection or pathology? Trends Parasitol [Internet]. 2013 Jan [cited 2015 Oct 14];29(1):26-34. Available from:

http://www.sciencedirect.com/science/article/pii/S1471492212001808

12. Moxon CA, Grau GE, Craig AG. Malaria: modification of the red blood cell and consequences in the human host. Br J Haematol [Internet]. 2011 Sep [cited 2015 Aug 13];154(6):670-9. Available from:

http://www.pubmedcentral.nih.gov/articlerender.fcgi?artid=3557659\&tool=pmcentrez\&re ndertype $=$ abstract

13. Stoute JA. Complement receptor 1 and malaria. Cell Microbiol [Internet]. 2011 Oct [cited 2015 Oct 14];13(10):1441-50. Available from:

http://www.ncbi.nlm.nih.gov/pubmed/21790941

14. Serghides L, Patel SN, Ayi K, Kain KC. Placental chondroitin sulfate A-binding malarial isolates evade innate phagocytic clearance. J Infect Dis [Internet]. 2006 Jul 1 [cited 2015 Sep 14];194(1):133-9. Available from: http://www.ncbi.nlm.nih.gov/pubmed/16741892

15. Couper KN, Barnes T, Hafalla JCR, Combes V, Ryffel B, Secher T, et al. Parasitederived plasma microparticles contribute significantly to malaria infection-induced inflammation through potent macrophage stimulation. PLoS Pathog [Internet]. 2010 Jan [cited 2015 Oct 14];6(1):e1000744. Available from:

http://www.pubmedcentral.nih.gov/articlerender.fcgi?artid=2813278\&tool=pmcentrez\&re ndertype $=$ abstract

16. Dasari P, Heber SD, Beisele M, Torzewski M, Reifenberg K, Orning C, et al. Digestive vacuole of Plasmodium falciparum released during erythrocyte rupture dually activates complement and coagulation. Blood [Internet]. 2012 May 3 [cited 2015 Oct 14];119(18):4301-10. Available from: http://www.ncbi.nlm.nih.gov/pubmed/22403252

17. Pratt-Riccio LR, Bianco C, Totino PRR, Perce-Da-Silva DDS, Silva LA, Riccio EKP, et al. Antibodies against the Plasmodium falciparum glutamate-rich protein from naturally exposed individuals living in a Brazilian malaria-endemic area can inhibit in vitro parasite growth. Mem Inst Oswaldo Cruz [Internet]. 2011 Aug [cited 2015 Oct 14];106 Suppl :3443. Available from: http://www.ncbi.nlm.nih.gov/pubmed/21881755 
18. Bouharoun-Tayoun $\mathrm{H}$, Oeuvray $\mathrm{C}$, Lunel F, Druilhe P. Mechanisms underlying the monocyte-mediated antibody-dependent killing of Plasmodium falciparum asexual blood stages. J Exp Med [Internet]. 1995 Aug 1 [cited 2015 Oct 14];182(2):409-18. Available from:

http://www.pubmedcentral.nih.gov/articlerender.fcgi?artid=2192140\&tool=pmcentrez\&re ndertype $=$ abstract

19. Ferlazzo G, Tsang ML, Moretta L, Melioli G, Steinman RM, Münz C. Human dendritic cells activate resting natural killer (NK) cells and are recognized via the NKp30 receptor by activated NK cells. J Exp Med [Internet]. 2002 Feb 4 [cited 2015 Oct 14];195(3):34351. Available from:

http://www.pubmedcentral.nih.gov/articlerender.fcgi?artid=2193591\&tool=pmcentrez\&re ndertype $=$ abstract

20. Steinman RM, Hemmi H. Dendritic cells: translating innate to adaptive immunity. Curr Top Microbiol Immunol [Internet]. 2006 Jan [cited 2015 Oct 21];311:17-58. Available from: http://www.ncbi.nlm.nih.gov/pubmed/17048704

21. Overstreet MG, Chen Y-C, Cockburn I a, Tse S-W, Zavala F. CD4+ T cells modulate expansion and survival but not functional properties of effector and memory CD8+ T cells induced by malaria sporozoites. PLoS One [Internet]. 2011 Jan [cited 2013 Sep 29];6(1):e15948. Available from:

http://www.pubmedcentral.nih.gov/articlerender.fcgi?artid=3014941\&tool=pmcentrez\&re ndertype $=$ abstract

22. Cockburn IA, Chen Y-C, Overstreet MG, Lees JR, van Rooijen N, Farber DL, et al. Prolonged antigen presentation is required for optimal CD8+ $T$ cell responses against malaria liver stage parasites. PLoS Pathog [Internet]. 2010 May [cited 2013 Sep 29];6(5):e1000877. Available from:

http://www.pubmedcentral.nih.gov/articlerender.fcgi?artid=2865532\&tool=pmcentrez\&re ndertype $=$ abstract

23. Perlaza B-L, Sauzet J-P, Brahimi K, BenMohamed L, Druilhe P. Interferon- $\mathrm{Y}$, a valuable surrogate marker of Plasmodium falciparum pre-erythrocytic stages protective immunity. Malar J [Internet]. 2011 Jan [cited 2013 Sep 29];10(1):27. Available from:

http://www.pubmedcentral.nih.gov/articlerender.fcgi?artid=3046914\&tool=pmcentrez\&re ndertype=abstract

24. Lumsden JM, Cranmer MA, Krzych U. An early commitment to expression of a particular TCRVbeta chain on CD8(+) T cells responding to attenuated Plasmodium berghei sporozoites is maintained following challenge with infectious sporozoites. Parasite Immunol [Internet]. Jan [cited 2013 Sep 29];32(9-10):644-55. Available from: http://www.ncbi.nlm.nih.gov/pubmed/20691016

25. Balam S, Romero JF, Bongfen SE, Guillaume P, Corradin G. CSP--a model for in vivo presentation of Plasmodium berghei sporozoite antigens by hepatocytes. PLoS One [Internet]. 2012 Jan [cited 2014 Oct 8];7(12):e51875. Available from: http://www.pubmedcentral.nih.gov/articlerender.fcgi?artid=3525584\&tool=pmcentrez\&re ndertype $=$ abstract 
26. Seder RA, Chang L-J, Enama ME, Zephir KL, Sarwar UN, Gordon IJ, et al. Protection Against Malaria by Intravenous Immunization with a Nonreplicating Sporozoite Vaccine. Science [Internet]. 2013 Aug 8 [cited 2013 Sep 19];341(6152):1359-65. Available from: http://www.sciencemag.org/content/341/6152/1359.abstract

27. Schwartz L, Brown G V, Genton B, Moorthy VS. A review of malaria vaccine clinical projects based on the WHO rainbow table. Malar J [Internet]. 2012 Jan [cited 2015 Oct 27];11:11. Available from:

http://www.pubmedcentral.nih.gov/articlerender.fcgi?artid=3286401\&tool=pmcentrez\&re ndertype $=$ abstract

28. Hawiger D, Inaba K, Dorsett $\mathrm{Y}$, Guo M, Mahnke K, Rivera M, et al. Dendritic cells induce peripheral T cell unresponsiveness under steady state conditions in vivo. J Exp Med [Internet]. 2001 Sep 17;194(6):769-79. Available from:

http://www.pubmedcentral.nih.gov/articlerender.fcgi?artid=2195961\&tool=pmcentrez\&re ndertype $=$ abstract

29. Trumpfheller C, Finke JS, López CB, Moran TM, Moltedo B, Soares H, et al. Intensified and protective CD4+ T cell immunity in mice with anti-dendritic cell HIV gag fusion antibody vaccine. J Exp Med [Internet]. 2006 Mar 20 [cited 2014 Oct 8];203(3):607-17. Available from:

http://www.pubmedcentral.nih.gov/articlerender.fcgi?artid=2118242\&tool=pmcentrez\&re ndertype $=$ abstract

30. Pulendran B, Palucka K, Banchereau J. Sensing pathogens and tuning immune responses. Science [Internet]. 2001 Jul 13 [cited 2013 Sep 29];293(5528):253-6.

Available from: http://www.ncbi.nlm.nih.gov/pubmed/11452116

31. Steinman RM. Dendritic cells in vivo: a key target for a new vaccine science. Immunity [Internet]. 2008 Sep 19 [cited 2013 Sep 27];29(3):319-24. Available from:

http://www.ncbi.nlm.nih.gov/pubmed/18799140

32. Shortman K, Naik SH. Steady-state and inflammatory dendritic-cell development. Nat Rev Immunol [Internet]. 2007 Jan [cited 2013 Sep 23];7(1):19-30. Available from: http://www.ncbi.nlm.nih.gov/pubmed/17170756

33. Villadangos $\mathrm{J}$ a, Schnorrer $\mathrm{P}$. Intrinsic and cooperative antigen-presenting functions of dendritic-cell subsets in vivo. Nat Rev Immunol [Internet]. 2007 Jul [cited 2013 Sep 24];7(7):543-55. Available from: http://www.ncbi.nlm.nih.gov/pubmed/17589544

34. Merad M, Sathe P, Helft J, Miller J, Mortha A. The dendritic cell lineage: ontogeny and function of dendritic cells and their subsets in the steady state and the inflamed setting. Annu Rev Immunol [Internet]. 2013 Jan [cited 2014 Jul 9];31:563-604. Available from: http://www.pubmedcentral.nih.gov/articlerender.fcgi?artid=3853342\&tool=pmcentrez\&re ndertype $=$ abstract 
35. Geijtenbeek TBH, van Vliet SJ, Engering A, 't Hart B a, van Kooyk Y. Self- and nonselfrecognition by C-type lectins on dendritic cells. Annu Rev Immunol [Internet]. 2004 Jan [cited 2012 Mar 5];22:33-54. Available from:

http://www.ncbi.nlm.nih.gov/pubmed/15032573

36. Dudziak D, Kamphorst AO, Heidkamp GF, Buchholz VR, Trumpfheller C, Yamazaki S, et al. Differential antigen processing by dendritic cell subsets in vivo. Science [Internet]. 2007 Jan 5 [cited 2012 Mar 8];315(5808):107-11. Available from: http://www.ncbi.nlm.nih.gov/pubmed/17204652

37. Maldonado-López R, De Smedt T, Michel P, Godfroid J, Pajak B, Heirman C, et al. CD8alpha+ and CD8alpha- subclasses of dendritic cells direct the development of distinct T helper cells in vivo. J Exp Med [Internet]. 1999 Mar 1 [cited 2013 Sep 29];189(3):587-92. Available from:

http://www.pubmedcentral.nih.gov/articlerender.fcgi?artid=2192907\&tool=pmcentrez\&re ndertype $=$ abstract

38. Mashayekhi M, Sandau MM, Dunay IR, Frickel EM, Khan A, Goldszmid RS, et al. CD8 $\alpha(+)$ dendritic cells are the critical source of interleukin-12 that controls acute infection by Toxoplasma gondii tachyzoites. Immunity [Internet]. 2011 Aug 26 [cited 2013 Sep 29];35(2):249-59. Available from:

http://www.pubmedcentral.nih.gov/articlerender.fcgi?artid=3171793\&tool=pmcentrez\&re ndertype $=$ abstract

39. Bonifaz LC, Bonnyay DP, Charalambous A, Darguste DI, Fujii S-I, Soares H, et al. In vivo targeting of antigens to maturing dendritic cells via the DEC-205 receptor improves T cell vaccination. J Exp Med [Internet]. 2004 Mar 15 [cited 2013 Sep 24];199(6):815-24 . Available from:

http://www.pubmedcentral.nih.gov/articlerender.fcgi?artid=2212731\&tool=pmcentrez\&re ndertype $=$ abstract

40. Bonifaz L, Bonnyay D, Mahnke K, Rivera M, Nussenzweig MC, Steinman RM. Efficient Targeting of Protein Antigen to the Dendritic Cell Receptor DEC-205 in the Steady State Leads to Antigen Presentation on Major Histocompatibility Complex Class I Products and Peripheral CD8+ T Cell Tolerance. J Exp Med [Internet]. 2002 Dec 9 [cited 2014 Sep 15];196(12):1627-38. Available from: http://www.jem.org/cgi/doi/10.1084/jem.20021598

41. Ko H-J, Chung J-Y, Nasa Z, Chan J, Siatskas C, Toh B-H, et al. Targeting MOG expression to dendritic cells delays onset of experimental autoimmune disease. Autoimmunity [Internet]. 2011 May [cited 2013 Sep 29];44(3):177-87. Available from: http://www.ncbi.nlm.nih.gov/pubmed/20883147

42. Pan W, Ravot E, Tolle R, Frank R, Mosbach R, Türbachova I, et al. Vaccine candidate MSP-1 from Plasmodium falciparum: a redesigned 4917 bp polynucleotide enables synthesis and isolation of full-length protein from Escherichia coli and mammalian cells. Nucleic Acids Res [Internet]. 1999 Mar 15;27(4):1094-103. Available from: http://www.pubmedcentral.nih.gov/articlerender.fcgi?artid=148291\&tool=pmcentrez\&ren dertype=abstract 
43. Boscardin SB, Hafalla JCR, Masilamani RF, Kamphorst AO, Zebroski H a, Rai U, et al. Antigen targeting to dendritic cells elicits long-lived T cell help for antibody responses. $J$ Exp Med [Internet]. 2006 Mar 20 [cited 2012 Mar 16];203(3):599-606. Available from: http://www.pubmedcentral.nih.gov/articlerender.fcgi?artid=2118236\&tool=pmcentrez\&re ndertype $=$ abstract

44. Fehres CM, Garcia-Vallejo JJ, Unger WWJ, van Kooyk Y. Skin-resident antigenpresenting cells: instruction manual for vaccine development. Front Immunol [Internet]. 2013 Jan [cited 2013 Sep 29];4(June):157. Available from:

http://www.pubmedcentral.nih.gov/articlerender.fcgi?artid=3687254\&tool=pmcentrez\&re ndertype $=$ abstract

45. Cheong C, Choi J-H, Vitale L, He L-Z, Trumpfheller C, Bozzacco L, et al. Improved cellular and humoral immune responses in vivo following targeting of HIV Gag to dendritic cells within human anti-human DEC205 monoclonal antibody. Blood [Internet]. 2010 Nov 11 [cited 2012 Mar 4];116(19):3828-38. Available from:

http://www.pubmedcentral.nih.gov/articlerender.fcgi?artid=2981538\&tool=pmcentrez\&re ndertype $=$ abstract

46. Do Y, Park CG, Kang Y-S, Park SH, Lynch RM, Lee H, et al. Broad T cell immunity to the LcrV virulence protein is induced by targeted delivery to DEC-205/CD205-positive mouse dendritic cells. Eur J Immunol [Internet]. 2008 Jan [cited 2012 May 30];38(1):209. Available from:

http://www.pubmedcentral.nih.gov/articlerender.fcgi?artid=2864640\&tool=pmcentrez\&re ndertype $=$ abstract

47. Bradford MM. A rapid and sensitive method for the quantitation of microgram quantities of protein utilizing the principle of protein-dye binding. Anal Biochem [Internet]. 1976 May 7 [cited 2014 Jul 9];72:248-54. Available from:

http://www.ncbi.nlm.nih.gov/pubmed/942051

48. Wilson NS, Behrens GMN, Lundie RJ, Smith CM, Waithman J, Young L, et al. Systemic activation of dendritic cells by Toll-like receptor ligands or malaria infection impairs cross-presentation and antiviral immunity. Nat Immunol [Internet]. $2006 \mathrm{Mar}$ [cited 2015 Nov 30];7(2):165-72. Available from: http://dx.doi.org/10.1038/ni1300

49. Wilson NS, Behrens GMN, Lundie RJ, Smith CM, Waithman J, Young L, et al. Systemic activation of dendritic cells by Toll-like receptor ligands or malaria infection impairs cross-presentation and antiviral immunity. Nat Immunol [Internet]. 2006 Mar [cited 2013 Sep 29];7(2):165-72. Available from: http://www.ncbi.nlm.nih.gov/pubmed/16415871

50. Birkholz K, Schwenkert M, Kellner C, Gross S, Fey G, Schuler-Thurner B, et al. Targeting of DEC-205 on human dendritic cells results in efficient MHC class II-restricted antigen presentation. Blood [Internet]. 2010 Sep 30 [cited 2012 Apr 7];116(13):2277-85. Available from: http://www.ncbi.nlm.nih.gov/pubmed/20566893

51. Proetzel GEH. Antibody Methods and Protocols. 2012. 297 p. 